\title{
The type IV mucolipidosis-associated protein TRPML1 is an endolysosomal iron release channel
}

\author{
Xian-Ping Dong ${ }^{1}$, Xiping Cheng ${ }^{1}$, Eric Mills ${ }^{1}$, Markus Delling ${ }^{2}$, Fudi Wang ${ }^{3}$, Tino Kurz $^{4} \&$ Haoxing Xu ${ }^{1}$
}

TRPML1 (mucolipin 1, also known as MCOLN1) is predicted to be an intracellular late endosomal and lysosomal ion channel protein that belongs to the mucolipin subfamily of transient receptor potential (TRP) proteins ${ }^{1-3}$. Mutations in the human TRPML1 gene cause mucolipidosis type IV disease (ML4) $)^{4,5}$. ML4 patients have motor impairment, mental retardation, retinal degeneration and iron-deficiency anaemia. Because aberrant iron metabolism may cause neural and retinal degeneration ${ }^{6,7}$, it may be a primary cause of ML4 phenotypes. In most mammalian cells, release of iron from endosomes and lysosomes after iron uptake by endocytosis of $\mathrm{Fe}^{3+}$-bound transferrin receptors ${ }^{6}$, or after lysosomal degradation of ferritin-iron complexes and autophagic ingestion of ironcontaining macromolecules ${ }^{6,8}$, is the chief source of cellular iron. The divalent metal transporter protein DMT1 (also known as SLC11A2) is the only endosomal $\mathrm{Fe}^{2+}$ transporter known at present and it is highly expressed in erythroid precursors ${ }^{6,9}$. Genetic studies, however, suggest the existence of a DMT1independent endosomal and lysosomal $\mathrm{Fe}^{2+}$ transport protein?. By measuring radiolabelled iron uptake, by monitoring the levels of cytosolic and intralysosomal iron and by directly patch-clamping the late endosomal and lysosomal membrane, here we show that TRPML1 functions as a $\mathrm{Fe}^{2+}$ permeable channel in late endosomes and lysosomes. ML4 mutations are shown to impair the ability of TRPML1 to permeate $\mathrm{Fe}^{2+}$ at varying degrees, which correlate well with the disease severity. A comparison of TRPML1 $1^{-1-}$ ML4 and control human skin fibroblasts showed a reduction in cytosolic $\mathrm{Fe}^{2+}$ levels, an increase in intralysosomal $\mathrm{Fe}^{2+}$ levels and an accumulation of lipofuscin-like molecules in TRPML1 ${ }^{-1-}$ cells. We propose that TRPML1 mediates a mechanism by which $\mathrm{Fe}^{2+}$ is released from late endosomes and lysosomes. Our results indicate that impaired iron transport may contribute to both haematological and degenerative symptoms of ML4 patients.

Release of $\mathrm{Fe}^{2+}$ from late endosomes and lysosomes into the cytosol is essential for cellular iron metabolism (see Supplementary Fig. 1) ${ }^{6}$. Because TRPML1 is ubiquitously expressed (in cells of every tissue $)^{5}$ and primarily localized in the late endosome and lysosome $(\mathrm{LEL})^{1,3,10}$, we propose that TRPML1 may act as an endolysosomal $\mathrm{Fe}^{2+}$ release channel. The intracellular localization of wild-type TRPML1 (refs 1, 3 and 10; see also Supplementary Fig. 2), however, makes it difficult to assay the function of this channel. To overcome this problem, we recently developed a functional assay for TRPML channels ${ }^{11}$. A spontaneous mouse mutation (A419P) ${ }^{12}$ markedly increases TRPML3-mediated currents at the plasma membrane without altering its permeation properties ${ }^{11}$. Mice carrying this mutation (varitint-waddler, $\mathrm{Va}$ ) are deaf and show skin pigmentation defects. When the $V a$ mutation (proline substitution) was introduced into a homologous position in TRPML1 (V432P), the mutant channel
TRPML1 $^{\mathrm{Va}}$ was (mis)localized in many cellular compartments including both LEL and the plasma membrane (Supplementary Fig. 2). Notably, TRPML1 ${ }^{\text {Va }}$, but not wild-type TRPML1, generated a cationic whole-cell current that can be measured by patch clamp ${ }^{11}$.

We studied TRPML proteins by transiently expressing them in HEK293T cell lines. To monitor expression, TRPML channels were fused to enhanced green fluorescent protein (EGFP) at their amino termini. In response to a voltage step protocol, TRPML1 ${ }^{\mathrm{Va}}$-expressing cells showed strong inwardly rectifying step currents (Fig. 1a and Supplementary Fig. 3) in a standard extracellular bath solution (a modified Tyrode's solution). TRPML1 ${ }^{\mathrm{Va}}$-mediated current $\left(I_{\text {TRPML1 }}\right.$ va $)$ was $101 \pm 8.6 \mathrm{pA} \mathrm{pF}^{-1}$ at $-80 \mathrm{mV}$ (mean \pm s.e.m., $n=48$ ). To mimic the acidic environments of lysosomes where the extracellular side (analogous to the intralysosomal luminal side) of the wild-type TRPML1 protein is exposed to, extracellular solutions were adjusted to $\mathrm{pH}$ 4.6. No sizable inward current was detected when $\mathrm{N}$-methyl-D-glucamine $\left(\mathrm{NMDG}^{+}\right)$was the only major cation in the bath ( $\mathrm{pH} 4.6$; Fig. $1 \mathrm{~b}$ ), indicating that $I_{\text {TRPML1va }}$ is a protonimpermeable cationic current ${ }^{11}$. Bath perfusion of $30 \mathrm{mM}$ extracellular $\left[\mathrm{Fe}^{2+}\right]\left(\left[\mathrm{Fe}^{2+}\right]_{0}, \mathrm{pH} 4.6\right)$ to TRPML1 ${ }^{\mathrm{Va}}$-expressing cells induced large inwardly rectifying currents (Fig. 1c). The current density of $\left[\mathrm{Fe}^{2+}\right]_{\mathrm{o}}$-elicited $I_{\mathrm{TRPML1}}{ }^{\mathrm{va}}\left(I_{\mathrm{Fe} / \mathrm{TRPML} 1^{\mathrm{Va}}}\right)$ at $-80 \mathrm{mV}$ was $74 \pm 8.6 \mathrm{pA} \mathrm{pF}^{-1}$ (mean \pm s.e.m., $n=24$ ). To keep $\mathrm{Fe}^{2+}$ in a reduced state, ascorbic acid was used as the counter anion in the bath solution. The only other main cation in the $30 \mathrm{mM} \mathrm{Fe}^{2+}$ solution was $\mathrm{NMDG}^{+}$. Thus, $I_{\mathrm{Fe} / \mathrm{TRPML} 1}{ }^{\mathrm{va}}$ is carried solely by Fe ${ }^{2+}$. Consistent with this, the amplitude of $I_{\mathrm{Fe} / \mathrm{TRPML} 1^{\mathrm{va}}}$ was strongly dependent on $\left[\mathrm{Fe}^{2+}\right]_{\mathrm{o}}$ (Supplementary Fig. 4).

Both $I_{\text {Fe/TRPML1va }}$ (Fig. 1e) and $I_{\text {TRPML1va }}{ }^{11}$ were enhanced at low $\mathrm{pH}$. Compared to experiments conducted at physiological $\mathrm{pH}$ (7.4), $I_{\mathrm{Fe} / T R P M L 1} 1^{\mathrm{va}}$ was enhanced $\sim 2$-fold at $\mathrm{pH} 4.6$ (approximately the luminal $\mathrm{pH}$ of lysosomes). In cells transfected with TRPML2 ${ }^{\mathrm{Va}}$ (a short splice variant; see Methods), a large current $(23.0 \pm 3.8$ $\mathrm{pA} \mathrm{pF}^{-1}$ at $\left.-80 \mathrm{mV}, n=7\right)$ was evoked by $30 \mathrm{mM} \mathrm{Fe}^{2+}(\mathrm{pH} 4.6$, Fig. 1e). Similar to $I_{\text {TRPML1va }} I_{\text {TRPML2 }}{ }^{\text {va }}$ was also strongly potentiated by low $\mathrm{pH}$ (Supplementary Fig. 5). The ratio of $I_{\mathrm{Fe}} / I_{\text {Tyrode }}$ for TRPML2 ${ }^{\mathrm{Va}}$ was $139 \pm 22 \%$ (at $-80 \mathrm{mV}, n=7$ ), which was even larger than the ratio for TRPML1 ${ }^{\mathrm{Va}}(72 \pm 7 \%, n=11)$. In contrast with TRPML1 ${ }^{\mathrm{Va}}$ and TRPML2 ${ }^{\mathrm{Va}}$, the ratio of $I_{\mathrm{Fe}} / I_{\text {Tyrode }}$ for TRPML3 $3^{\mathrm{Va}}$ was only $2.3 \pm 0.2 \%(n=8$; Fig. $1 \mathrm{f})$. Thus, Fe ${ }^{2+}$ permeability is specific for TRPML1 and TRPML2, but not for the closely related TRPML3. Cationic selectivity analysis suggested that TRPML1 ${ }^{\text {Va }}$ was also permeable to most other divalent trace metals including $\mathrm{Mn}^{2+}$ and $\mathrm{Zn}^{2+}$, but not to $\mathrm{Fe}^{3+}$ (Supplementary Fig. 6). Detailed analyses of the permeation properties of TRPML1 ${ }^{\mathrm{Va}}$ suggested that the conduction mechanism of $\mathrm{Fe}^{2+}$ resembled those of $\mathrm{Na}^{+}$and $\mathrm{Ca}^{2+}$ (see Supplementary Figs 7-9).

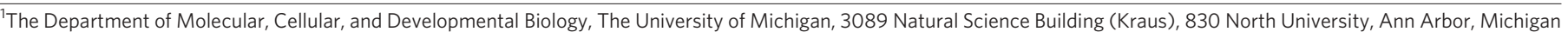

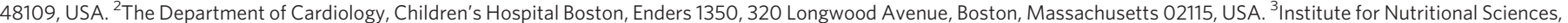

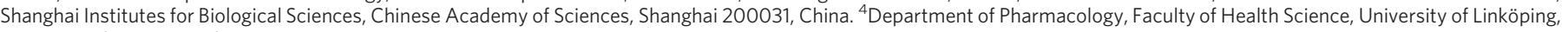
S-58185 Linköping, Sweden. 

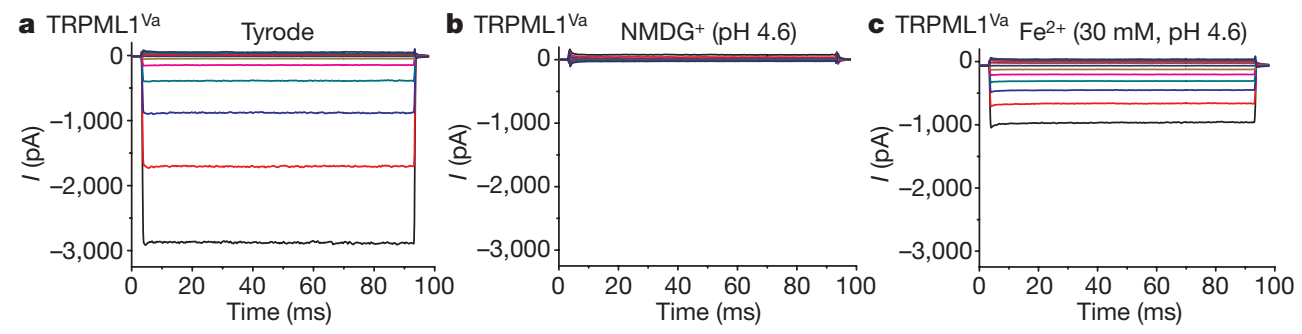
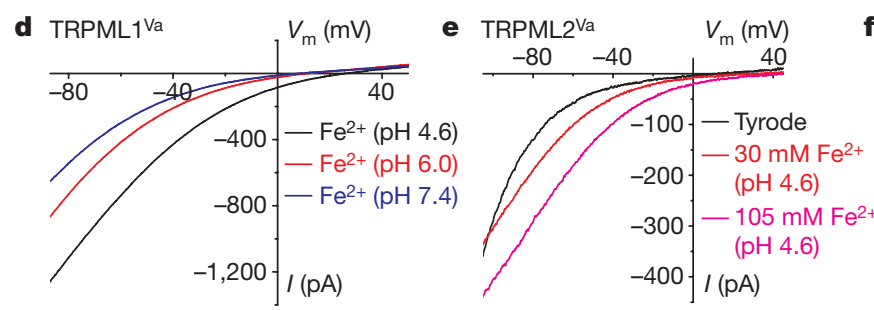

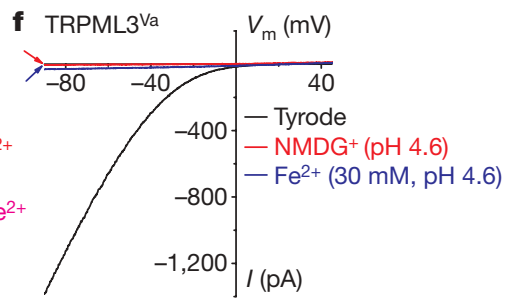

Figure 1 | TRPML1 ${ }^{\mathrm{Va}}$-expressing cells have a constitutively active $\mathrm{H}^{+}$modulated $\mathrm{Fe}^{2+}$ current. a, A TRPML1 ${ }^{\mathrm{Va}}$-expressing HEK293T cell showed a large inwardly rectifying whole-cell current elicited by voltage steps (from $-140 \mathrm{mV}$ to $+80 \mathrm{mV}$ in increments of $20 \mathrm{mV}$ ) in the standard extracellular (Tyrode's) bath solution. Step duration, $90 \mathrm{~ms}$; holding potential, $0 \mathrm{mV} ; V_{\mathrm{m}}$, membrane potential. $\mathbf{b}$, No significant inward current was detected in $\mathrm{NMDG}^{+}\left(\mathrm{Na}^{+}\right.$-free, $\mathrm{Ca}^{2+}$-free, $\mathrm{pH}$ 4.6) solution. c, Inwardly rectifying step currents were evoked by $30 \mathrm{mM} \mathrm{Fe}{ }^{2+}$ solution ( $\left.\mathrm{pH} 4.6\right)$ in the same cell as

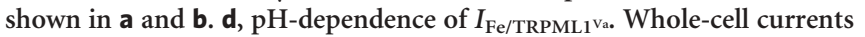
were elicited by repeated voltage ramps $(-100$ to $+100 \mathrm{mV} ; 400 \mathrm{~ms})$ with a 4 -s interval between ramps. Only a portion of the voltage protocol is shown. Holding potential, $0 \mathrm{mV}$. e, Large $I_{\mathrm{Fe} / \mathrm{TRPML} 2^{\mathrm{Va}}}$ was seen in the presence of 30 and $105 \mathrm{mM} \mathrm{Fe}^{2+}\left(\mathrm{pH}\right.$ 4.6). f, Little or no $I_{\mathrm{Fe}}$ was seen in a TRPML $3^{\mathrm{Va}}$ expressing cell.
Next, we tested whether the $\mathrm{Fe}^{2+}$ permeability of TRPML1 is impaired by ML4 mutations. More than 15 ML4 mutations have been identified, most of which are located in the transmembrane regions of TRPML1 (Supplementary Fig. 10) 4,5,13,14. We constructed six of these ML4 mutants into the TRPML1 ${ }^{\mathrm{Va}}$ background and investigated the $\mathrm{Fe}^{2+}$ permeability of these combined mutations. We found that all ML4 mutant TRPML1 ${ }^{\mathrm{Va}}$ channels had significantly smaller $I_{\mathrm{Fe}}$ than TRPML1 ${ }^{\mathrm{Va}}$. In particular, T232P, D362Y and V446L mutations (combined with the $V a$ mutation) completely eliminated $I_{\mathrm{Fe}}$, as well as $I_{\text {Tyrode }}$ (Fig. 2a and Supplementary Fig. 11), although the protein expression levels and subcellular localization pattern of these mutants were similar to those of the parental TRPML1 $^{\text {Va }}$ protein (Supplementary Figs 12 and 13). Patients carrying these mutations are reported to have severe phenotypes ${ }^{5,15}$. On the other hand, a large $I_{\mathrm{Fe}}$ was detected in F408D-TRPML1 ${ }^{\mathrm{Va}}$-transfected cells. The average current density of this mutant, however, was still significantly smaller than $I_{\mathrm{Fe} / \mathrm{TRPML1}}$ a. Patients carrying the F408 $\Delta$ mutation have unusually mild phenotypes ${ }^{13,15}$. Small but evident $I_{\mathrm{Fe}}$ was detected with expression of two other mutants (R403C and $\mathrm{F} 465 \mathrm{~L}$ ). A patient carrying the R403C mutation was reported to have a relatively mild phenotype ${ }^{14}$. Taken together, these results

Figure $2 \mid \mathrm{Fe}^{2+}$ permeability of the TRPML1 channel is impaired by ML4 mutations. a, Current densities (mean \pm s.e.m., $n=4-10)$ of $I_{\mathrm{Fe}}(30 \mathrm{mM}$ $\mathrm{Fe}^{2+}, \mathrm{pH}$ 4.6) for TRPML1 ${ }^{\mathrm{Va}}$ and ML4 mutant TRPML1 ${ }^{\mathrm{Va}}$ channels. Asterisk indicates statistical difference $(P<0.01)$ compared to TRPML1 ${ }^{\mathrm{Va}}$. b, ${ }^{55} \mathrm{Fe}^{2+}$ uptake (normalized) in HEK293T cells transfected with vector control, with TRPML1 ${ }^{\mathrm{Va}}$, with F408 $\Delta$-TRPML1 ${ }^{\mathrm{Va}}$ and with T232PTRPML $1{ }^{\mathrm{Va}}$ constructs. Error bars indicate the standard deviation on the basis of two independent triplicate experiments. $\mathbf{c},\left[\mathrm{Fe}^{2+}\right]_{0}$-dependent quenching of Fura-2 fluorescence in TRPML1 ${ }^{\mathrm{Va}}$-transfected cells (arrows), but not in non-transfected control cells (arrowheads) or T232P-TRPML1 ${ }^{\text {Va }}$ transfected cells (bottom row). The fluorescence intensity was measured at an excitation wavelength of $360 \mathrm{~nm}\left(F_{360}\right)$. The original magnification used for all micrographs was $\times 200$. d, Average normalized responses of EGFPpositive TRPML $1^{\mathrm{Va}}$-transfected cells (typically $n=20-40$ cells) to 1 or $10 \mathrm{mM} \mathrm{Fe}^{2+}$ (pH 4.6). e, No significant quenching was seen in T232PTRPML1 ${ }^{\mathrm{Va}}$-transfected cells. $f$, Slightly less quenching was observed for the F408 $\Delta$-TRPML1 ${ }^{\mathrm{Va}}$-expressing cells. g, A small but significant quenching reaction was detected (with $10 \mathrm{mM} \mathrm{Fe}^{2+}$ ) in R403C-TRPML1 ${ }^{\mathrm{Va}}$-expressing cells.
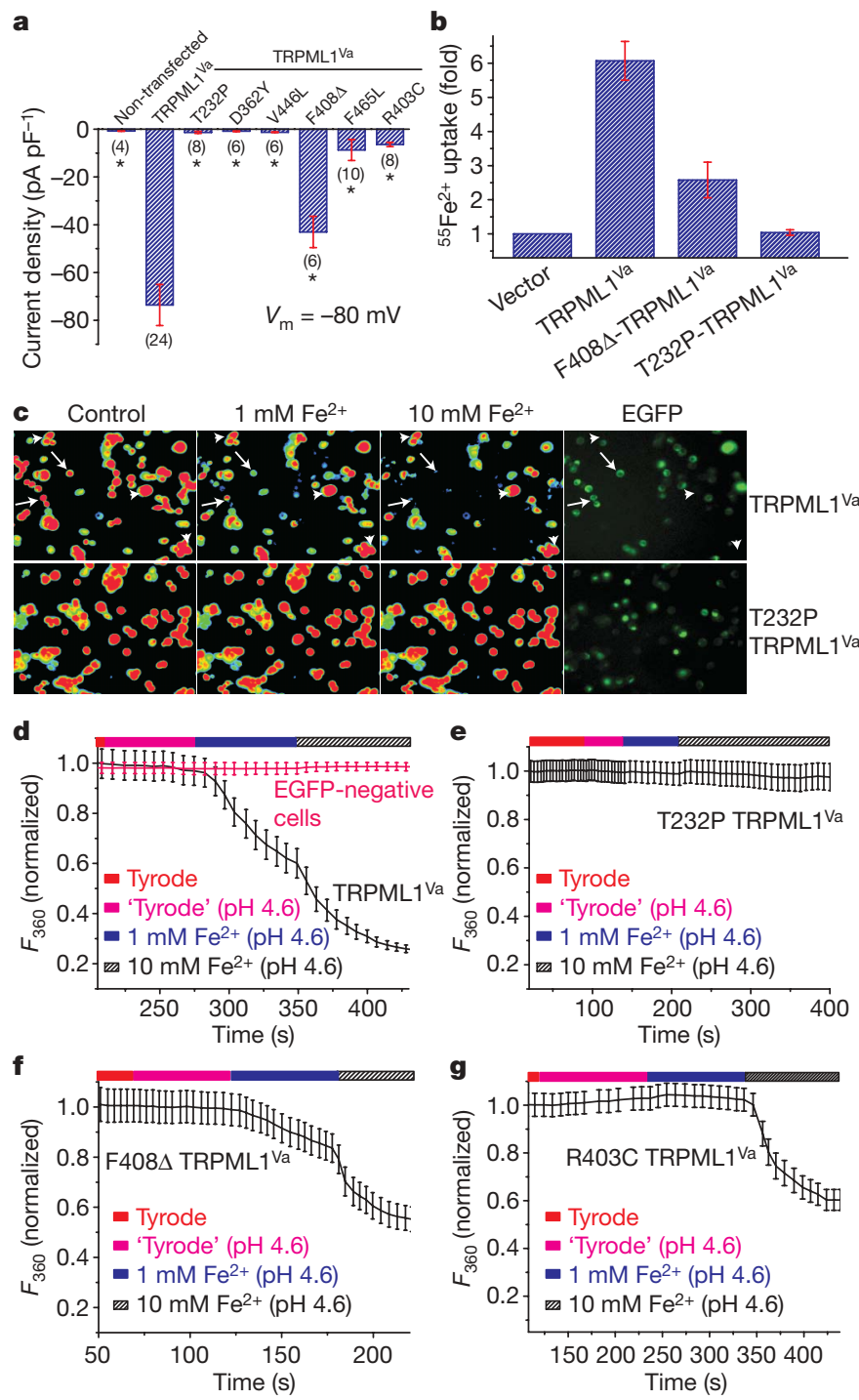
indicate that ML4 mutations significantly impair the $\mathrm{Fe}^{2+}$ permeability of TRPML1. The degree of the impaired $\mathrm{Fe}^{2+}$ permeability seems to correlate well with disease severity observed in ML4 patients.

To investigate TRPML1 ${ }^{\mathrm{Va}}$-mediated $\mathrm{Fe}^{2+}$ influx under less invasive conditions in intact cells, we measured ${ }^{55} \mathrm{Fe}^{2+}$ uptake at low $\mathrm{pH}$ ( $\mathrm{pH}$ 5.8, $1 \mu \mathrm{M}^{55} \mathrm{Fe}^{2+}$; Fig. 2b). Significant ${ }^{55} \mathrm{Fe}^{2+}$ uptake was seen in HEK293T cells transfected with TRPML1 ${ }^{\mathrm{Va}}$, but not with T232PTRPML1 ${ }^{\mathrm{Va}}$. An intermediate ${ }^{55} \mathrm{Fe}^{2+}$ uptake was seen for $\mathrm{F} 408 \Delta$ TRPML1 $^{\mathrm{Va}}$. These results indicate that TRPML1 ${ }^{\mathrm{Va}}$ can mediate significant $\mathrm{Fe}^{2+}$ entry even at micromolar $\left[\mathrm{Fe}^{2+}\right]_{\mathrm{o}}$. We also adopted a fluorescence-based $\mathrm{Fe}^{2+}$ quenching assay to measure TRPML1 ${ }^{\mathrm{Va}}$ mediated $\mathrm{Fe}^{2+}$ entry in HEK293T cells. Heavy metals such as $\mathrm{Mn}^{2+}$ and $\mathrm{Fe}^{2+}$ can bind $\mathrm{Ca}^{2+}$-sensitive dyes such as Fura- 2 with higher affinity, resulting in strong fluorescence quenching effects ${ }^{16}$. Substantial quenching of Fura-2 fluorescence was seen in
TRPML1 ${ }^{\mathrm{Va}}$-expressing cells after the addition of $1 \mathrm{mM} \mathrm{Fe} \mathrm{Fe}^{2+}$ (pH 4.6; Fig. 2d, f). Increased quenching was observed with the addition of higher concentrations of $\mathrm{Fe}^{2+}(10 \mathrm{mM}, \mathrm{pH} 4.6)$. In contrast, no significant quenching was detected in neighbouring non-transfected EGFP-negative cells or TRPML3 ${ }^{\mathrm{Va}}$-transfected cells $(1 \mathrm{mM}$ $\mathrm{Fe}^{2+}$; Supplementary Fig. 14). ML4 mutant TRPML1 ${ }^{\mathrm{Va}}$-expressing HEK293T cells showed an impairment of $\mathrm{Fe}^{2+}$ quenching. No significant $\mathrm{Fe}^{2+}$ quenching was seen in T232P- (Fig. 2e), D362Y-, or V446L-TRPML1 ${ }^{\mathrm{Va}}$-expressing cells (data not shown). Slightly less quenching was observed for F408 $\Delta$-TRPML1 ${ }^{\text {Va }}$ (Fig. 2f). In contrast, R403C-TRPML1 ${ }^{\text {Va }}$ (Fig. 2g) and F465L-TRPML1 ${ }^{\text {Va }}$ showed no response to the addition of $1 \mathrm{mM} \mathrm{Fe}^{2+}$. However, a higher concentration of $\mathrm{Fe}^{2+}(10 \mathrm{mM})$ induced a slow but significant quenching. These results agree with the electrophysiological measurements of ML4 mutants, as well as the disease severity of ML4 patients carrying a
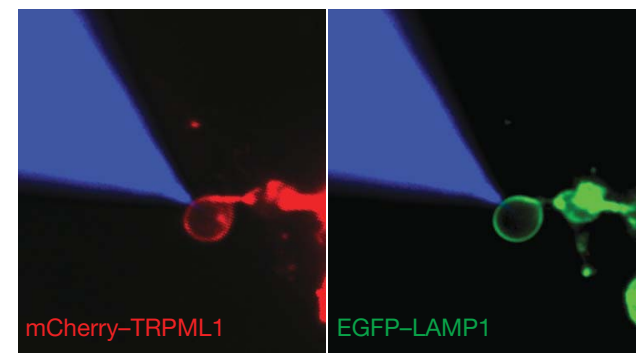

b

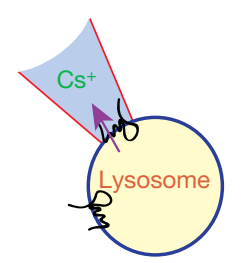

Lysosome-attached

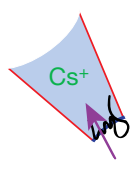

Lysosome luminal-side-out

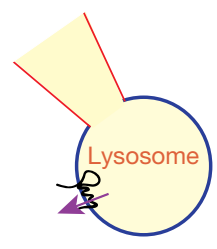

Whole-lysosome

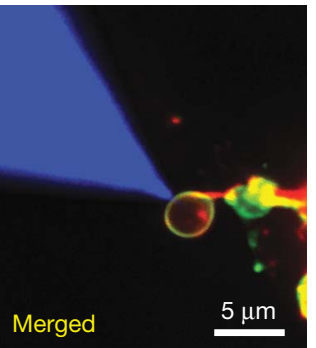

\section{c TRPML1Va}

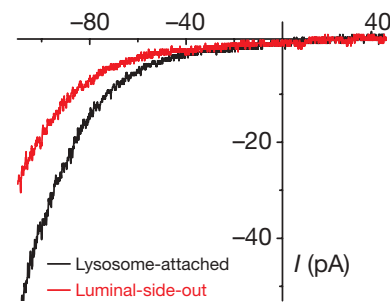

d Luminal-side-out (TRPML1Va)

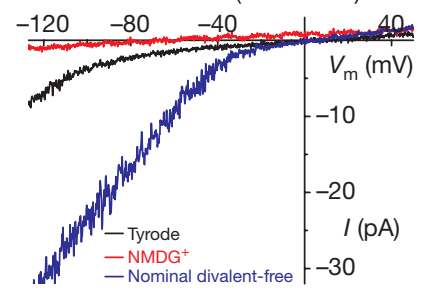

g Whole-lysosome (TRPML1)

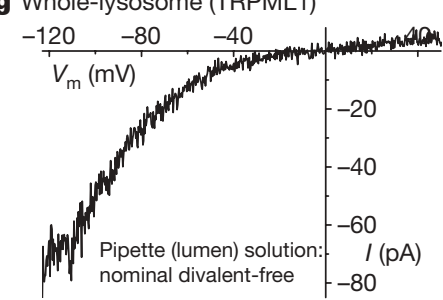

e Luminal-side-out (TRPML1Va)

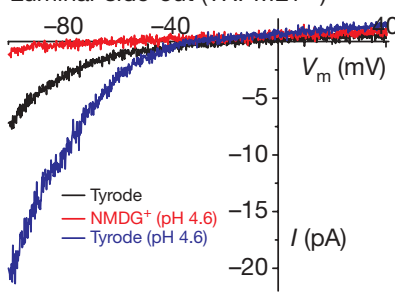

h Whole-lysosome (TRPML1 $1^{\mathrm{Va}}$ )

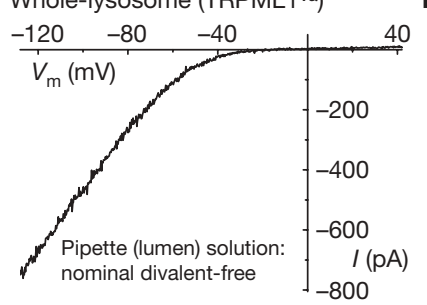

f Luminal-side-out (TRPML1 1 aa)

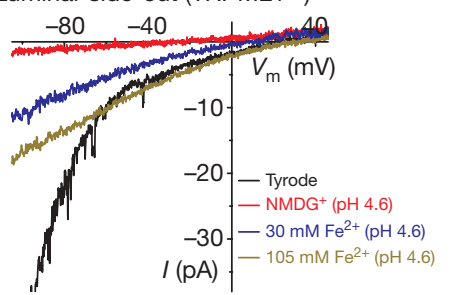

i Whole-lysosome (TRPML1)

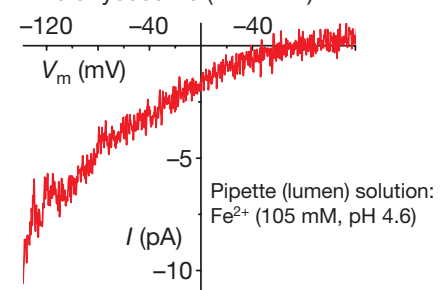

Figure 3 | TRPML1 conducts $\mathrm{Fe}^{2+}$ in late endosomes and lysosomes. a, Colocalization of mCherry-TRPML1 and EGFP-LAMP1 at the membrane of an isolated enlarged LEL (see Methods). The patch pipette was filled with red rhodamine B dye (shown in blue for the purpose of illustration). $\mathbf{b}$, Cartoons of three distinct patch-clamp configurations of lysosomal recordings: lysosome-attached, lysosome luminal-side-out and whole-lysosome. In each configuration, the pink arrow indicates the direction of the inward (at negative potentials; flow out of the lysosomes) current mediated by TRPML1 (as shown in c-i). c, Lysosomal $I_{\mathrm{TRPML1}}{ }^{\mathrm{Va}}$. Switching from lysosome-attached to (lysosome) luminal-side-out configuration significantly reduced the amplitude of the current. The luminal-side-out patch was exposed to the
Tyrode's solution. A Cs ${ }^{+}$-based solution (147 mM Cs-methanesulphonate (Cs-MSA)) was used as a pipette solution for both configurations.

d, $\mathrm{NMDG}^{+}$-impermeable lysosomal $I_{\mathrm{TRPML1}^{\mathrm{va}}}$ was much larger in the absence of divalent cations (nominal divalent-free). e, Lowering $\mathrm{pH}$ potentiated lysosomal $I_{\text {TRPML1Va. }}$ f, $I_{\mathrm{Fe} / \mathrm{TRPML1}}$ induced by $30 \mathrm{mM}$ and $105 \mathrm{mM} \mathrm{Fe}^{2+} . \mathrm{g}$, Whole-lysosome current in an enlarged lysosome expressing wild-type TRPML1. The pipette (lumen) solution contained nominal divalent-free Tyrode solution. A Cs ${ }^{+}$-based bath solution $(147 \mathrm{mM}$ Cs-MSA) was used. h, Whole-lysosome $I_{\text {TRPML1 }}{ }^{\text {va. }}$ i, Whole-lysosome $I_{\mathrm{Fe} / \mathrm{TRPML} 1}$. The pipette (lumen) solution contained $105 \mathrm{mM} \mathrm{Fe}^{2+}$ (pH 4.6). 
these mutations ${ }^{5,13-15}$. Thus, ML4 phenotypes result from a loss-offunction of TRPML1 with respect to $\mathrm{Fe}^{2+}$ and/or $\mathrm{Ca}^{2+}$ permeability.

To validate our use of TRPML1 ${ }^{\mathrm{Va}}$ as a model to extrapolate potential intracellular functions of wild-type TRPML1, and more importantly, to confirm whether wild-type TRPML1 conducts $\mathrm{Fe}^{2+}$ from the lumen of LEL into the cytosol, we performed patch-clamp recordings directly on native LEL membranes (Fig. $3 \mathrm{a}$ and Supplementary Fig. 15; see Methods). In TRPML1 ${ }^{\mathrm{Va}}$-positive enlarged LEL, large inwardly rectifying currents were seen under the lysosome-attached configuration (Fig. 3b, c). The currents became smaller when the patch was excised (lysosome luminalside-out) and exposed to Tyrode's solution (Fig. 3c). These large inwardly rectifying currents were not seen in TRPML1 ${ }^{\mathrm{Va}}$-negative vacuoles, suggesting that these lysosomal currents are mediated by TRPML1 $^{\text {Va }}$ (hereafter referred to as lysosomal $I_{\text {TRPML1 }}$ va $)$. Note that inward lysosomal currents are actually currents that flow out of the lysosomes. Similar to $I_{\text {TRPML1va }}$ recorded at the plasma membrane, lysosomal $I_{\text {TRPML1 }}$ va was impermeable to $\mathrm{NMDG}^{+}$and $\mathrm{H}^{+}$, but was potentiated by low $\mathrm{pH}$ or by removal of divalent cations in the bath solution (nominal divalent-free; Fig. 3d, e). When the luminal-sideout patches were exposed to $30 \mathrm{mM}$ or $105 \mathrm{mM} \mathrm{Fe}^{2+}$ solutions ( $\mathrm{pH}$ 4.6), smaller and less rectifying currents were seen, resembling $I_{\mathrm{Fe} / \mathrm{TRPML}} \mathrm{I}_{\mathrm{va}}$ at the plasma membrane. These results indicate that TRPML1 ${ }^{\text {Va }}$ behaves similarly at both plasma and lysosomal membranes. Likewise, ML4 mutant TRPML1 ${ }^{\mathrm{Va}}$ channels also behaved similarly as their plasma membrane counterparts (Supplementary Fig. 16), consistent with our conclusion that ML4 mutations primarily affect the channel function of TRPML1.

Next we performed whole-lysosome recordings on enlarged LEL expressing wild-type TRPML1 and TRPML1 ${ }^{\text {Va }}$. Significant inwardly rectifying currents were seen in wild-type TRPML1-positive LEL $\left(81.0 \pm 9.0 \mathrm{pA} \mathrm{pF}^{-1}\right.$ at $-120 \mathrm{mV}, n=6$; Fig. $\left.3 \mathrm{~g}\right)$ with nominal divalent-free solution in the luminal side (that is, pipette solution), although the current amplitude is still one order of magnitude smaller than the whole-lysosome current recorded from TRPML1 ${ }^{\mathrm{Va}}$-positive LEL $\left(1,713 \pm 404 \mathrm{pA} \mathrm{pF}^{-1}\right.$ at $-120 \mathrm{mV}, n=4$; Fig. $\left.3 \mathrm{~h}\right)$. Because we were not able to record any significant whole-cell current from wild-type TRPML1-expressing HEK293T cells ${ }^{11}$, our results indicate that the $V a$ mutation affects both channel gating and trafficking (between LEL and the plasma membrane) of TRPML1. When isotonic $(105 \mathrm{mM}) \mathrm{Fe}^{2+}$ solution was included in the luminal side of wild-type TRPML1-positive enlarged LEL, inwardly rectifying currents with very positive reversal potential were observed $\left(18 \pm 4 \mathrm{pA} \mathrm{pF}^{-1}\right.$ at $-120 \mathrm{mV}, n=4$; Fig. $\left.3 \mathrm{i}\right)$. Collectively, these results indicate that wild-type TRPML1 is a lysosomal $\mathrm{Fe}^{2+}$-permeable channel, and that the $\mathrm{Va}$ mutation does not alter the permeation properties of the TRPML1 channel.

Retention of $\mathrm{Fe}^{2+}$ in LEL due to loss or inactivation of the $\mathrm{Fe}^{2+}$ release mechanism may result in an insufficient supply of cytosolic $\mathrm{Fe}^{2+}$. We therefore measured the levels of free (chelatable) intracellular $\mathrm{Fe}^{2+}$ in skin fibroblasts from a ML4 patient $\left(\right.$ TRPML1 $\left.^{-1-}\right)$ and the non-diseased parent $\left(T R P M L 1^{+/-}\right)$using a fluorescence-based iron de-quenching imaging method (see Methods) ${ }^{17}$. Chelatable $\mathrm{Fe}^{2+}$ levels were significantly lower in TRPML1 $1^{-1-}$ cells compared to the control TRPML1 ${ }^{+/-}$cells (Fig. 4a, b). TRPML1-deficient skin fibroblast cells show autofluorescence (Fig. 4c) at excitation wavelengths between $440 \mathrm{~nm}$ and $500 \mathrm{~nm}$, reminiscent of accumulated lipofuscin-like substances previously reported ${ }^{18}$. The autofluorescence observed was primarily localized in LAMP1 (a marker for LEL)-positive compartments (Fig. 4c), indicative of a lysosomal dysfunction in TRPML1 $1^{-1-}$ cells. Lipofuscin, also referred to as an 'ageing pigment', is a non-degradable oxidized polymeric substance containing proteins, lipids, carbohydrates and iron ${ }^{19}$. The production of lipofuscin is facilitated by increased intralysosomal $\mathrm{Fe}^{2+}$ levels ${ }^{19}$. Our results indicate that an accumulation of autofluorescent lipofuscinlike molecules in TRPML1 $1^{-/-}$cells might result from impaired intralysosomal iron metabolism. Consistent with this, lysosomal iron staining experiments showed that TRPML1 ${ }^{-1-}$ cells had higher lysosomal iron content than control cells (Supplementary Fig. 17).

We have demonstrated that TRPML1 has a critical role in cellular iron homeostasis by showing the cytosolic $\mathrm{Fe}^{2+}$ deficiency with concurrent intralysosomal iron overload in ML4 cells. ML4 cells show a defect in the late endocytic pathway ${ }^{10,20,21}$, suggesting that TRPML1 may be required for $\mathrm{Ca}^{2+}$-dependent fusion or fission of LEL. However, this defect in vesicular transport cannot explain the cytosolic $\mathrm{Fe}^{2+}$ deficiency that we observed because the internalization and recycling of the transferrin receptor is normal in ML4 cells ${ }^{20}$, and lysosomal $\mathrm{Fe}^{2+}$ release (into the cytosol) is probably mediated directly by an iron-conducting channel/transporter, as is the case for DMT1 (ref. 22). Therefore, by far the simplest explanation of our results is that the $\mathrm{Fe}^{2+}$ release pathway between the cytosol and the lysosome lumen is blocked or inactivated in cells with ML4 mutations. Although a ML4-induced loss of $\mathrm{Ca}^{2+}$ permeability may result in a defect in lysosomal trafficking and subsequent accumulation of various lipids in LEL, the degradation of these materials is normal ${ }^{20,21}$. Therefore, these accumulated substances would become most harmful only if they are oxidized to generate lipofuscin-like non-degradable materials in the presence of high intralysosomal $\mathrm{Fe}^{2+}$ (ref. 19). Lipofuscin-like molecules preferentially accumulate in post-mitotic cells such as muscle cells and neurons, which are primarily affected in ML4 patients ${ }^{21}$. Our work suggests that lysosome-targeting iron chelators might alleviate the degenerative symptoms of ML4 patients.
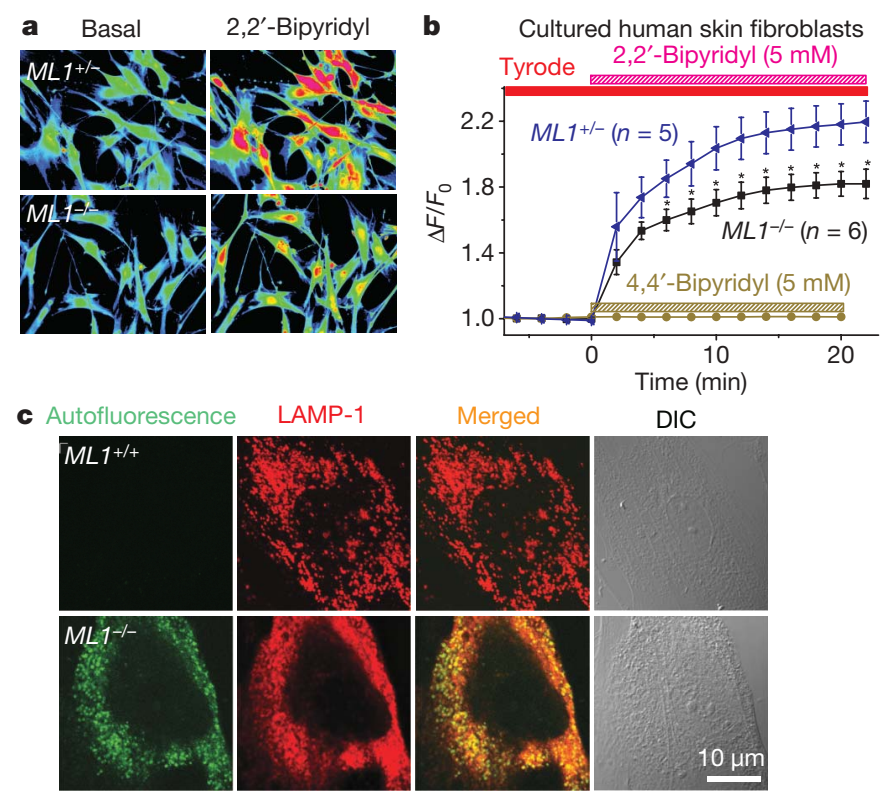

DIC

Figure 4 | TRPML1-deficient cells have reduced free (chelatable) iron levels and lysosomal autofluorescence. a, Cultured TRPML1 $1^{-/-}\left(\mathrm{ML}^{-/-}\right)$ skin fibroblasts showed less de-quenching of the iron-sensitive fluorescence than $M L 1^{+/-}$cells did. De-quenching was achieved by preloading the fibroblasts with an iron-sensitive dye, Phen Green SK (PG SK), and then adding the membrane-permeable transition metal chelator, 2,2' -bipyridyl (BPD). 2,2'-BPD is predicted to chelate free cellular iron (also referred to as chelatable or labile iron), which subsequently increases PG SK fluorescence. The original magnification used was $\times 200$. b. The average $2,2^{\prime}-\mathrm{BPD}$ induced normalized change of fluorescence $\left(\Delta F / F_{0}\right)$ for ML4 cells $\left(M L 1^{-/-} ; n=6\right.$ experiments) is significantly (asterisk, $P<0.01$ ) lower than for the parental $M L 1^{+/-}$cells. Fibroblast cells $(n=10-20)$ were analysed for each individual experiment. $4,4^{\prime}-\mathrm{BPD}$, a $2,2^{\prime}-\mathrm{BPD}$ analogue that cannot bind $\mathrm{Fe}^{2+}$, did not induce any significant restoration of PG SK fluorescence. Error bars, s.e.m. c, An $M L 1^{-1-}$ skin fibroblast cell showed autofluorescence in LAMP1positive compartments. Autofluorescence (green) was detected within a range of excitation wavelengths (shown with excitation at $480 \mathrm{~nm}$ ). No significant autofluorescence was observed for a $M L 1^{+/+}$cell. Lysosomes were stained with a LAMP1 antibody (red). Differential interference contrast (DIC) images are shown for comparison. 
From the cell biology perspective, an important question to address is how TRPML channels are regulated by various cytosolic and luminal factors, and/or by proteins and lipids in the LEL membrane, especially those of which are known to be involved in endolysosomal trafficking.

\section{METHODS SUMMARY}

Endolysosomal electrophysiology. HEK293T cells were either transfected with EGFP-TRPML1 alone or co-transfected with mCherry-TRPML1 and EGFPLAMP1 (a marker for LEL). The size of the LEL is usually $<0.5 \mu \mathrm{m}$, which is suboptimal for patch clamping. We therefore treated cells with $1 \mu \mathrm{M}$ vacuolin-1 (for 1-2 h), a small chemical known to increase the size of endosomes and lysosomes selectivel ${ }^{23}$. Large vacuoles (up to $3 \mu \mathrm{m}$; capacitance $=321 \pm 101 \mathrm{fF}, n=11$ ) were observed in most vacuolin-treated cells (Supplementary Fig. 15). Occasionally, enlarged LEL could also been obtained from TRPML1-transfected cells without vacuolin-1 treatment. No significant difference in TRPML channel properties was seen for enlarged LEL with or without vacuolin-1 treatment. The vacuoles that were positive for both mCherry-TRPML1 and EGFP-LAMP1 were considered as enlarged LEL. Whole-lysosome, lysosome-attached and lysosome luminal-side-out recordings were performed on isolated enlarged LEL, similar to what was performed in enlarged endosomes ${ }^{24}$. In brief, a patch pipette (electrode) was pressed against a cell and then quickly pulled away from the cell to slice the cell membrane. Enlarged LEL were released into the dish and identified by monitoring the TRPML1-EGFP, the TRPML1-mCherry or the LAMP1EGFP fluorescence.

Iron quenching imaging. HEK293T cells were loaded with $5 \mu \mathrm{M}$ Fura-2 AM (Molecular Probes) in culture medium at $37^{\circ} \mathrm{C}$ for $60 \mathrm{~min}$. Cells were washed in Tyrode's solution for $10-30 \mathrm{~min}$ and fluorescence intensity at wavelength $360 \mathrm{~nm}\left(F_{360}\right)$ was recorded on an EasyRatioPro system (Photon Technology International). EGFP-positive cells were identified by monitoring fluorescence intensity at wavelength $470 \mathrm{~nm}\left(F_{470}\right)$. Images were analysed using ERP software.

Full Methods and any associated references are available in the online version of the paper at www.nature.com/nature.

\section{Received 26 March; accepted 1 August 2008.}

Published online 14 September 2008.

1. Venkatachalam, K., Hofmann, T. \& Montell, C. Lysosomal localization of TRPML3 depends on TRPML2 and the mucolipidosis-associated protein TRPML1. J. Biol. Chem. 281, 17517-17527 (2006).

2. Clapham, D. E. TRP channels as cellular sensors. Nature 426, 517-524 (2003).

3. Nilius, B., Owsianik, G., Voets, T. \& Peters, J. A. Transient receptor potential cation channels in disease. Physiol. Rev. 87, 165-217 (2007).

4. Bassi, M. T. et al. Cloning of the gene encoding a novel integral membrane protein, mucolipidin-and identification of the two major founder mutations causing mucolipidosis type IV. Am. J. Hum. Genet. 67, 1110-1120 (2000).

5. Sun, M. et al. Mucolipidosis type IV is caused by mutations in a gene encoding a novel transient receptor potential channel. Hum. Mol. Genet. 9, 2471-2478 (2000).

6. Hentze, M. W., Muckenthaler, M. U. \& Andrews, N. C. Balancing acts: molecular control of mammalian iron metabolism. Cell 117, 285-297 (2004).

7. Lee, D. W., Andersen, J. K. \& Kaur, D. Iron dysregulation and neurodegeneration: the molecular connection. Mol. Interv. 6, 89-97 (2006).
8. Kidane, T. Z., Sauble, E. \& Linder, M. C. Release of iron from ferritin requires lysosomal activity. Am. J. Physiol. Cell Physiol. 291, C445-C455 (2006).

9. Gunshin, H. et al. Slc11a2 is required for intestinal iron absorption and erythropoiesis but dispensable in placenta and liver. J. Clin. Invest. 115, 1258-1266 (2005).

10. Pryor, P. R., Reimann, F., Gribble, F. M. \& Luzio, J. P. Mucolipin-1 is a lysosomal membrane protein required for intracellular lactosylceramide traffic. Traffic 7 , 1388-1398 (2006).

11. Xu, H., Delling, M., Li, L., Dong, X. \& Clapham, D. E. Activating mutation in a mucolipin transient receptor potential channel leads to melanocyte loss in varitint-waddler mice. Proc. Natl Acad. Sci. USA 104, 18321-18326 (2007).

12. Di Palma, F. et al. Mutations in Mcoln3 associated with deafness and pigmentation defects in varitint-waddler (Va) mice. Proc. Natl Acad. Sci. USA 99, 14994-14999 (2002).

13. Altarescu, G. et al. The neurogenetics of mucolipidosis type IV. Neurology 59, 306-313 (2002).

14. Goldin, E. et al. Transfer of a mitochondrial DNA fragment to MCOLN1 causes an inherited case of mucolipidosis IV. Hum. Mutat. 24, 460-465 (2004).

15. Bargal, R., Goebel, H. H., Latta, E. \& Bach, G. Mucolipidosis IV: novel mutation and diverse ultrastructural spectrum in the skin. Neuropediatrics 33, 199-202 (2002).

16. Kress, G. J., Dineley, K. E. \& Reynolds, I. J. The relationship between intracellular free iron and cell injury in cultured neurons, astrocytes, and oligodendrocytes. J. Neurosci. 22, 5848-5855 (2002).

17. Petrat, F., de Groot, H. \& Rauen, U. Determination of the chelatable iron pool of single intact cells by laser scanning microscopy. Arch. Biochem. Biophys. 376, 74-81 (2000).

18. Goldin, E., Blanchette-Mackie, E. J., Dwyer, N. K., Pentchev, P. G. \& Brady, R. O Cultured skin fibroblasts derived from patients with mucolipidosis 4 are autofluorescent. Pediatr. Res. 37, 687-692 (1995).

19. Kurz, T., Terman, A., Gustafsson, B. \& Brunk, U. T. Lysosomes in iron metabolism, ageing and apoptosis. Histochem. Cell Biol. 129, 389-406 (2008).

20. Chen, C. S., Bach, G. \& Pagano, R. E. Abnormal transport along the lysosomal pathway in mucolipidosis, type IV disease. Proc. Natl Acad. Sci. USA 95, 6373-6378 (1998).

21. Zeevi, D. A., Frumkin, A. \& Bach, G. TRPML and lysosomal function. Biochim. Biophys. Acta. 1772, 851-858 (2007).

22. Andrews, N. C. \& Schmidt, P. J. Iron homeostasis. Annu. Rev. Physiol. 69, 69-85 (2007).

23. Cerny, J. et al. The small chemical vacuolin-1 inhibits $\mathrm{Ca}^{2+}$-dependent lysosomal exocytosis but not cell resealing. EMBO Rep. 5, 883-888 (2004).

24. Saito, M., Hanson, P. I. \& Schlesinger, P. Luminal chloride-dependent activation of endosome calcium channels: patch clamp study of enlarged endosomes. J. Biol. Chem. 282, 27327-27333 (2007).

Supplementary Information is linked to the online version of the paper at www.nature.com/nature.

Acknowledgements This work is supported by start-up funds to H.X. from the Department of Molecular, Cellular, and Developmental Biology and Biological Science Scholar Program, University of Michigan. We thank U. Brunk, M. Saito,

R. Hume, C. Duan, M. Akaaboune, J. Kuwada, S. Low, S. Punthambaker and S. Dellal for assistance, and D. Clapham, N. Andrews, L. DeFelice, L. Yue, D. Ren, C. Jiang and $\mathrm{S}$. Xu for comments on an earlier version of the manuscript. We also thank $\mathrm{K}$. Kiselyov for sharing his unpublished results on lysosomal iron staining of ML4 cells. We appreciate the encouragement and helpful comments from other members of the Xu laboratory.

Author Information Reprints and permissions information is available at www.nature.com/reprints. Correspondence and requests for materials should be addressed to H.X. (haoxingx@umich.edu). 


\section{METHODS}

Molecular biology and biochemistry. Full-length mouse TRPML1 and TRPML3, and a short splicing variant of mouse TRPML2 (GeneBank accession NP_001005846), were cloned into the EGFP-C2 vector (Clontech), the mCherry vector, or haemagglutinin-tag containing pcDNA3 as described previously ${ }^{11}$. No significant functional difference was observed among EGFP-tagged, mCherrytagged and haemagglutinin-tagged TRPML ${ }^{\mathrm{Va}}$ constructs. ML4 mutants were constructed on a TRPML1 ${ }^{\mathrm{Va}}$ background using a site-directed mutagenesis kit (Qiagen). All constructs were confirmed by sequencing analysis and protein expression was verified by western blotting. HEK293T cells were transiently transfected with wild-type TRPML1, TRPML1 ${ }^{\mathrm{Va}}$ and ML4 mutants for electrophysiology, confocal imaging, ${ }^{55} \mathrm{Fe}^{2+}$ uptake and $\mathrm{Fe}^{2+}$ quenching assays. TRPML1 western blot analyses were performed with an anti-EGFP monoclonal antibody (Covance).

Confocal imaging. All images were taken using a Leica (TCS SP5) confocal microscope. LAMP1 antibody was from the Iowa Hybridoma Bank and LysoTracker was from Molecular Probes (Invitrogen).

Mammalian cell electrophysiology. Recordings were performed in transiently transfected HEK293T cells. Cells were cultured at $37^{\circ} \mathrm{C}$, transfected using Lipofectamine 2000 (Invitrogen) and plated onto glass coverslips. No significant difference was observed for EGFP-tagged versus untagged TRPML1 ${ }^{\mathrm{Va}}$ transfected cells. Unless otherwise stated, pipette solution contained $147 \mathrm{mM}$ Cs, $120 \mathrm{mM}$ methanesulphonate (MSA), $4 \mathrm{mM} \mathrm{NaCl}, 10 \mathrm{mM}$ EGTA, $2 \mathrm{mM} \mathrm{Na}_{2}$ ATP, $2 \mathrm{mM} \mathrm{MgCl} 2,20 \mathrm{mM}$ HEPES (pH 7.2; free $\left[\mathrm{Ca}^{2+}\right]_{\mathrm{i}}<10 \mathrm{nM}$ ). Standard extracellular bath solution (modified Tyrode's solution) contained $153 \mathrm{mM}$ $\mathrm{NaCl}, 5 \mathrm{mM} \mathrm{KCl}, 2 \mathrm{mM} \mathrm{CaCl}, 1 \mathrm{mM} \mathrm{MgCl} 2,20 \mathrm{mM}$ HEPES and $10 \mathrm{mM}$ glucose (pH 7.4). To reduce the background from an endogenous $\mathrm{Cl}^{-}$conductance activated by protons that was strongly outwardly rectifying ${ }^{11,25}$, gluconate ${ }^{-}$or $\mathrm{MSA}^{-}$was used to replace most of the $\mathrm{Cl}^{-}$(remaining $\left[\mathrm{Cl}^{-}\right]_{\mathrm{o}}=5-10 \mathrm{mM}$ ) for all low-pH bath solutions. Low-pH 'Tyrode's' solution contained $150 \mathrm{mM} \mathrm{Na}$ gluconate, $5 \mathrm{mM} \mathrm{KCl}, 2 \mathrm{mM} \mathrm{CaCl}, 1 \mathrm{mM} \mathrm{MgCl}_{2}, 10 \mathrm{mM}$ glucose, $10 \mathrm{mM}$ HEPES and $10 \mathrm{mM}$ MES (pH 4.6). $\mathrm{NMDG}^{+}$solution contained $160 \mathrm{mM}$ NMDG, $20 \mathrm{mM}$ HEPES, $10 \mathrm{mM}$ glucose (pH 7.4). Low-pH $\mathrm{NMDG}^{+}$solution contained $150 \mathrm{mM}$ NMDG, $10 \mathrm{mM}$ glucose, $10 \mathrm{mM}$ MES, 10 HEPES ( $\mathrm{pH}$ adjusted to 4.6 using MSA). 'Isotonic' metal solutions contained $105 \mathrm{mM}$ metal ions, $30 \mathrm{mM}$ glucose, $10 \mathrm{mM}$ HEPES, $10 \mathrm{mM}$ MSA and 0-30 $\mathrm{mM} \mathrm{NMDG}^{+}$ ( $\mathrm{pH}$ 4.6). Further metal solutions $(1,3,10$ and $30 \mathrm{mM})$ were derived from mixing isotonic solutions with low-pH $\mathrm{NMDG}^{+}$solutions at various ratios. Monovalent (nominal divalent-free) solutions contained $10 \mathrm{mM}$ glucose, $20 \mathrm{mM}$ HEPES, $160 \mathrm{mM} \mathrm{NaCl}$ and $5 \mathrm{mM} \mathrm{KCl}\left(\mathrm{pH} 7.4\right.$; free $\left.\mathrm{Ca}^{2+}<1-10 \mu \mathrm{M}\right)$. All solutions were applied by a fast perfusion system to achieve a complete solution exchange within a few seconds. Data were collected using an Axopatch $2 \mathrm{~A}$ patch clamp amplifier, Digidata 1440 and pClamp 10.0 software (Axon Instruments). Whole-cell currents and single channel recordings were digitized at $10 \mathrm{kHz}$ and filtered at $2 \mathrm{kHz}$. Capacity current was reduced as much as possible using the amplifier circuitry. Series resistance compensation was $60 \%-85 \%$. All experiments were conducted at room temperature $\left(\sim 21-23^{\circ} \mathrm{C}\right)$ and all recordings were analysed with pCLAMP10 (Axon Instruments) and Origin 7.5 (Origin Lab).

Iron de-quenching imaging. Cultured skin fibroblast cells from a ML4 patient (TRPML1 $1^{-1-}$, clone WG0909) and corresponding heterozygous parent $\left(\right.$ TRPML1 $^{+/-}$, clone WG0987) were obtained from the Repository for Mutant Human Cell Strains of Montreal Children's Hospital (Montreal, Canada). Fibroblast cells were loaded with $20 \mu \mathrm{M}$ Phen Green SK (Molecular Probes) in culture medium at $37^{\circ} \mathrm{C}$ for $20 \mathrm{~min}$ followed by a $15 \mathrm{~min}$ wash. Cellular fluorescence was excited at $488 \mathrm{~nm}$ on the PTI ERP system. Quenching of fluorescence was induced by the addition of the membrane-permeable transition metal chelator 2,2'-bipyridyl $(5 \mathrm{mM})^{17}$. The 2,2' -bipyridyl analogue $4,4^{\prime}$-bipyridyl, which cannot bind or chelate $\mathrm{Fe}^{2+}$, was used as a control. Because many variables such as dye loading may contribute to the variation of basal fluorescence $(F)$ of PG SK, the normalized change of fluorescence $(\Delta F / F)$ was used as readout to estimate the change in cytosolic $\mathrm{Fe}^{2+}$ levels.

Iron uptake assay. Iron uptake was measured as described previously ${ }^{25}$. In brief, $30 \mathrm{~h}$ after transfection, HEK293T cells were washed twice with prewarmed PBS and then incubated with $1 \mathrm{ml}$ of prewarmed uptake assay buffer $(25 \mathrm{mM}$ Tris, $25 \mathrm{mM}$ MES, $140 \mathrm{mM} \mathrm{NaCl}, 5.4 \mathrm{mM} \mathrm{KCl}, 5 \mathrm{mM}$ glucose, $1.8 \mathrm{mM} \mathrm{CaCl}_{2}, 800 \mu \mathrm{M}$ $\mathrm{MgSO} 4,50 \mu \mathrm{M}$ ascorbic acid, pH 5.8) containing ${ }^{55} \mathrm{Fe}$-nitrilotriacetic acid (NTA, $1 \mu \mathrm{M}{ }^{55} \mathrm{Fe}$ ) at $37{ }^{\circ} \mathrm{C}$ for $5 \mathrm{~min} .{ }^{55} \mathrm{Fe}-\mathrm{NTA}$ was made by mixing ${ }^{55} \mathrm{FeCl}_{3}$ (PerkinElmer) with $100 \mathrm{mM} \mathrm{NTA}$ in a 1:50 molar ratio. Ascorbic acid (100 mM) was used to promote the formation and maintenance of ferrous $\left(\mathrm{Fe}^{2+}\right)$ iron (adjusted to $\mathrm{pH}$ 5.8). All uptake assays were performed with $20 \mu \mathrm{M} \mathrm{Fe}^{2+}$ (with a 1:20 molar ratio for ${ }^{55} \mathrm{FeCl}_{3}$ and $\mathrm{FeSO}_{4}$ ) at pH 5.8. Assays were stopped by the addition of $2 \mathrm{ml}$ ice-cold PBS. After washing three times with ice-cold PBS, the cells were detached and collected by adding $1 \mathrm{ml} 0.25 \%$ trypsin-EDTA. Parallel experiments were conducted at $0{ }^{\circ} \mathrm{C}$ to measure the cell surface ${ }^{55} \mathrm{Fe}$ binding, which was subtracted from the values at $37^{\circ} \mathrm{C}$ to obtain the net iron uptake. Cellassociated radioactivity was measured with liquid scintillation spectrometry. Lysosomal iron staining. Lysosome iron was stained using a modified sulphidesilver method ${ }^{19}$. In brief, fibroblast cells were grown on coverslips and exposed to $50 \mu \mathrm{M} \mathrm{Fe}^{3+}$-dextran overnight. Cells were then washed with PBS and fixed with $2 \%$ glutaraldehyde in $0.1 \mathrm{M} \mathrm{Na}$-cacodylate buffer with $0.1 \mathrm{M}$ sucrose ( $\mathrm{pH} 7.2$ ) for $1.5 \mathrm{~h}$ at room temperature $\left(22^{\circ} \mathrm{C}\right)$. Next cells were sulphidated at $\sim \mathrm{pH} 9$ with $1 \%(\mathrm{w} / \mathrm{v})$ ammonium sulphide in $70 \%(\mathrm{v} / \mathrm{v})$ ethanol for $15 \mathrm{~min}$. The development was then performed using a physical, colloid-protected developer containing silver-lactate and hydroquinone for $1-2 \mathrm{~h}$.

Reagents. 2,2'-BPD, 4,4'-BPD, iron ascorbate, ferric chloride, iron dextran, and all other metal salts were from Sigma Chemicals.

Data analysis. Most data are presented as the mean \pm s.e.m. Statistical comparisons were made using analysis of variance (ANOVA). A $P$ value $<0.05$ was considered statistically significant.

25. Xu, H., Jin, J., DeFelice, L. J., Andrews, N. C. \& Clapham, D. E. A spontaneous, recurrent mutation in divalent metal transporter-1 exposes a calcium entry pathway. PLOS Biol. 2, E50 (2004). 